\title{
The capability of reprogramming the male chromatin after fertilization is dependent on the quality of oocyte maturation
}

\author{
Luisa Gioia, Barbara Barboni, Maura Turriani, Giulia Capacchietti, Maria Gabriella Pistilli, \\ Paolo Berardinelli and Mauro Mattioli \\ Dipartimento di Scienze Biomediche Comparate, Fisiologia Veterinaria, Università di Teramo, Piazza Aldo Moro \\ 45, Teramo 64100, Italy
}

Correspondence should be addressed to L Gioia; Email: Igioia@unite.it

\begin{abstract}
The present experiments compared the ability of pig oocytes matured either in vivo or in vitro to structurally reorganize the penetrated sperm chromatin into male pronucleus (PN) and to carry out, in parallel, the epigenetic processes of global chromatin methylation and acetylation, 12-14 h after in vitro fertilization (IVF). In addition, PN distribution of histone deacetylase (HDAC), a major enzyme interfacing DNA methylation and histone acetylation, was investigated. The ability of the oocyte to operate an efficient block to polyspermy was markedly affected by maturation. The monospermic fertilization rate was significantly higher for in vivo than for in vitro matured (IVM) oocytes $(P<0.01)$ which, furthermore, showed a reduced ability to transform the chromatin of penetrated sperm into male PN $(P<0.01)$. Indirect immunofluorescence analysis of global DNA methylation, histone acetylation and HDAC distribution (HDAC-1, -2 and -3), carried out in monospermic zygotes that reached the late PN stage, showed that IVM oocytes also had a reduced epigenetic competence. In fact, while in about $80 \%$ of in vivo matured and IVF oocytes the male PN underwent a process of active demethylation and showed a condition of histone $\mathrm{H} 4$ hyperacetylation, only $40 \%$ of IVM/IVF zygotes displayed a similar PN remodelling asymmetry. Oocytes that carried out the first part of maturation in vivo (up to germinal vesicle breakdown; GVBD) and then completed the process in vitro, displayed the same PN asymmetry as oocytes matured entirely in vivo. A crucial role of HDAC in the establishment of PN acetylation asymmetry seems to be confirmed by the use of HDAC inhibitors as well as by the abnormal distribution of the enzyme between the two PN in IVM zygotes. Collectively, these data demonstrated that some pig IVM oocytes fail to acquire full remodelling competence which is independent from their ooplasmic ability to morphologically reorganize the sperm nucleus into PN.

Reproduction (2005) 130 29-39
\end{abstract}

\section{Introduction}

Many of the events that prepare the female gamete for fertilization and make it capable of supporting the initiation of embryonic development take place during oocyte maturation. Among these, cortical granule migration from subcortical to cortical regions (Cran \& Cheng 1985, Galeati et al. 1991) in order to operate an efficient exocytosis (Ducibella et al. 1990) at fertilization, the development of clusters of endoplasmic reticulum in the oocyte cortex (Mehlmann et al. 1995), the increase of calcium in intracellular stores (Mehlmann \& Kline 1994) to allow a prompt activation in response to fertilization (Carroll et al. 1994, Barboni \& Mattioli 1996) and the increase of cytosolic glutathione levels for the decondensation of penetrated sperm nucleus (Mattioli et al. 1996, Sutovsky \& Schatten 1997, Zuelke et al. 2003) are all essential steps for the acquisition of full developmental competence. More recently, it has been found that the parental chromatin remodelling that occurs before singamy appears to be the most sophisticated and complex task that the oocyte has to accomplish in order for embryo/fetal development to proceed regularly (McLay \& Clarke 2003).

The sperm nucleus, in fact, has a unique chromatin structure where the DNA is highly condensed, being associated with specific proteins, the protamines. This extremely packed chromatin organization is functional for the sperm, allowing a reduced cell size and a cell rigidity that are essential for penetration into the oocyte. However, in this condition, the sperm is associated with a reversible quiescence of the genome; there is no active RNA transcription or DNA replication (Ward \& Coffey 1991, Ward \& Zalensky 1996, Kramer \& Kravetz 1997). Therefore, once it has entered the oocyte, sperm chromatin has to be 
profoundly rearranged and made compatible with the maternal chromatin (Adenot et al. 1991, McLay \& Clarke 2003). Following sperm penetration into the cytoplasm of a mature oocyte, the highly condensed chromatin of the sperm nucleus first decondenses and the protamines are replaced by histones (Kopecny \& Pavlok 1975), after a short period of chromatin recondensation (Borsuk \& Manka 1988, Wright \& Longo 1988), a final phase of decondensation and the formation of the interphase male pronucleus $(\mathrm{PN})$, surrounded by a new organized pronuclear membrane, occurs. During this sperm chromatin structure reorganization, and particularly during protamine-histone replacement, profound DNA epigenetic modifications take place. In the same mature ooplasm and at the same time, the maternal genome is also modified and prepared for integration with the paternal genome.

DNA methylation and histone acetylation are the two major mechanisms adopted for introducing epigenetic modifications both in paternal and maternal genomes. Several recent reports indicate that methylation of $\mathrm{CpG}$ islands and acetylation of the nuclear core histones condition the level of gene expression (Sapienza et al. 1987, Wolfe \& Matzke 1999, Reik et al. 2001). In the early hours after fertilization, before DNA replication in the zygote, when the nuclear envelope breaks down and paternal chromosomes can directly interact with maternal cytosolic factors, the mature oocyte has to be able to operate a cycle where methylation patterns are reprogrammed genome-wide, but at the same time the epigenetic asymmetry established during imprinting between maternal and paternal genomes, still based on DNA methylation, has to be maintained (Reik et al. 2001). The arrangement of the cytoplasmic machinery required to carry out the above genome remodelling is most likely completed during oocyte maturation, as suggested by the findings of McLay \& Clarke (1997), when structural components as well as specific enzymes first appear within the oocyte.

Manipulative procedures, such as cloning, due to damages related to nuclear-cytoplasmic interactions, may alter the capability of the oocyte to correctly perform these epigenetic processes leading to abnormal embryo development (Niemann et al. 2002, McEvoy et al. 2003, Wrenzycki \& Niemann 2003). Moreover, the loss of imprinted gene marks can easily occur when the process of oocyte maturation is also carried out in vitro, invariably resulting in the developmental failure of embryos or leading to defective fetal programming (Niemann \& Wrenzycki 2000, Young et al. 2001). Despite the fact that more than 20 years have been dedicated to optimizing oocyte maturation in vitro in a number of species, in vitro matured (IVM) oocytes still have an overall developmental competence that is far from normal and the kind of developmental abnormalities that are more frequently recorded, such as the large offspring syndrome in ruminants, point to aberrant epigenetic changes as the probable underlying cause (Niemann \& Wrenzycki 2000, Niemann et al. 2002).
The ability of the oocyte to carry out the correct genome remodelling after fertilization therefore represents a solid opportunity to characterize oocyte maturation. For this reason, the knowledge of epigenetic processes in mammalian zygotes has acquired a particular relevance and several studies have addressed this issue in recent years. Results so far obtained demonstrate that active male DNA demethylation, originally recorded in the mouse (Mayer et al. 2000), is generally conserved in mammals (Dean et al. 2001), even though some differences for sheep and rabbits have been reported (Beaujean et al. 2004a, 2004b, Shi et al. 2004, Young \& Beaujean 2004), suggesting that genome-wide demethylation is not an obligatory requirement for epigenetic reprogramming. As far as the process of histone acetylation is concerned, the only indications reported deal with the mouse model (Worrad et al. 1995, Adenot et al. 1997).

The present research has been designed to correlate the ability of the pig oocyte to organize the sperm nucleus into the PN with the main epigenetic modifications (DNA methylation and histone acetylation) of maternal and paternal chromatin that occur in zygotes $12-14 \mathrm{~h}$ after in vitro fertilization (IVF), shortly before singamy. As reported by Laurincik et al. (1994), at this time-point zygotes obtained from pig oocytes matured in vivo or matured in vitro do not show developmental differences. Even though during the early hours (between 6 and $12 \mathrm{~h}$ ) after fertilization, male PN formation is delayed in most IVM oocytes (zygotes present asynchronous PN development, as compared with zygotes obtained from in vivo matured oocytes that already present synchronized PN $8 \mathrm{~h}$ after fertilization), during the next hours IVM oocytes present an acceleration of male PN formation and consequently between 12 and $14 \mathrm{~h}$ after IVF the developmental differences are no longer relevant in respect to in vivo matured oocytes. After this time (and until $32 \mathrm{~h}$ after fertilization) both PN develop in a well-synchronized manner. Therefore, in all our experiments, we utilized zygotes obtained from in vivo matured and IVM oocytes $12-14 \mathrm{~h}$ after IVF which did not present developmental differences and were characterized by the presence of synchronized opposing PN.

In order to verify whether structural and biochemical remodelling of male and female $\mathrm{PN}$ chromatin may be affected by the quality of the process of maturation, we studied, in parallel, three groups of oocytes: (a) oocytes that completed the whole process of maturation under in vitro conditions, (b) oocytes that resumed meiosis in vivo, up to germinal vesicle breakdown (GVBD), and completed the process in vitro and (c) in vivo matured oocytes.

The data presented here showed that IVM/IVF zygotes were characterized by a low ability to sustain monospermic fertilization as well as to develop well-synchronized $\mathrm{PN}$ and, in parallel, presented a reduced epigenetic competence. In fact, a high percentage of IVM zygotes fail to achieve demethylated DNA and hyperacetylated histone 
$\mathrm{H} 4$ of paternal origin, as recorded in oocytes that completed the process of maturation in vivo. This ability to organize the global remodelling of sperm chromatin at fertilization can be obtained when the first part of the process of maturation (up to GVBD) is carried out in vivo and involves, in part, the selective distribution of histone deacetylase (HDAC)-2 in parental PN.

\section{Materials and Methods}

\section{Source of oocytes}

\section{In vivo matured oocytes}

Sixty prepubertal Large White gilts, with an average weight of $90 \mathrm{~kg}$, were stimulated with $1250 \mathrm{IU}$ eqine chorionic gonadotrophin (Folligon; Intervet, Boxmer, The Netherlands) to induce follicular growth, followed, $60 \mathrm{~h}$ later, by $750 \mathrm{IU}$ human chorionic gonadotrophin (hCG; Corulon; Intervet) to trigger oocyte maturation and induce ovulation. Thirty-eight hours after hCG treatment (Tattini \& Mattioli 1988), animals were slaughtered to collect the ovaries. Follicles of $6-10 \mathrm{~mm}$ in diameter were isolated and mature cumulus oocyte complexes were incubated for $2 \mathrm{~h}$ in vitro in modified TCM 199 (Sigma, St Louis, MO, USA).

\section{IVM oocytes}

Ovaries were collected soon after slaughter from prepubertal gilts and transferred in saline solution to the laboratory within $1 \mathrm{~h}$. Healthy antral follicles $4-5 \mathrm{~mm}$ in diameter, selected on the basis of their translucent appearance, good vascularization and regular granulosa, were isolated under a stereomicroscope in Dulbecco's phosphate-buffered saline (PBS) supplemented with $0.4 \%(\mathrm{w} / \mathrm{v})$ bovine serum albumin (BSA) and $70 \mu \mathrm{g}$ kanamycin $/ \mathrm{ml}$. After isolation, the follicles were opened, turned inside out and incubated as everted follicles in a humidified atmosphere at $38.5^{\circ} \mathrm{C}$ with $5 \% \mathrm{CO}_{2}$ in air in TCM 199 supplemented with $10 \%(\mathrm{v} / \mathrm{v})$ fetal calf serum (FCS), $1 \mathrm{mmol}$ glutamine/l, $70 \mu \mathrm{g}$ kanamycin/ml, $1 \mu \mathrm{g}$ luteinizing hormone/ml and $1 \mu \mathrm{g}$ follicle-stimulating hormone/ml (USDA-pLH-B1 and USDA-pFSH-B1, kindly provided by the National Pituitary Hormone Distribution Program, NIDDK-NIH, Bethesda, MD, USA) to carry out oocyte maturation, according to Mattioli et al. (1989).

\section{In vivo/vitro matured oocytes}

As pig oocyte maturation is comparatively quite a long process, we were interested in assessing which part of maturation is more relevant for the acquisition of chromatin remodelling competence. With this aim, syncronized gilts were slaughtered $24 \mathrm{~h}$ after hCG injection, at about the time of GVBD. Follicles of $6-10 \mathrm{~mm}$ in diameter were isolated and incubated as everted follicles (Mattioli et al. 1989) to further mature oocytes for $20 \mathrm{~h}$ under in vitro conditions.

\section{IVF}

Oocytes collected at the end of in vivo, in vitro and in vivo/vitro maturation were mechanically denuded in dissection medium containing $0.1 \%(\mathrm{w} / \mathrm{v})$ hyaluronidase using a fine glass pipette and selected for the presence of a polar body. Mature oocytes were then incubated in a $50 \mu \mathrm{l}$ drop of fertilization medium (TCM 199; $10 \%(\mathrm{v} / \mathrm{v})$ FCS, $8.4 \mathrm{mmol}$ glucose $/ \mathrm{l}, 1.25 \mathrm{mmol}$ Na-piruvate/l, $5.45 \mathrm{mmol}$ calcium lactate/l and $2 \mathrm{mmol}$ caffeine/l) under mineral oil at $38.5^{\circ} \mathrm{C}$. Fresh semen from two boars of proven fertility was used for the IVF procedure. According to Barboni et al. (1995), for capacitation in vitro the semen was washed in PBS with $0.4 \%(w / v)$ BSA through two successive centrifugations at $800 \mathrm{~g}$ for $3 \mathrm{~min}$, than diluted in fertilization medium with $10 \%(\mathrm{v} / \mathrm{v})$ FCS at a final concentration of $2 \times 10^{8}$ spermatozoa $/ \mathrm{ml}$ and finally incubated for $2 \mathrm{~h}$ at $38.5^{\circ} \mathrm{C}$ in a $5 \% \mathrm{CO}_{2}$ atmosphere. After capacitation, a $50 \mu \mathrm{l}$ sperm aliquot was introduced in the fertilization drop to obtain a final concentration of $2 \times 10^{6}$ spermatozoa $/ \mathrm{ml}$. We utilized this sperm concentration which was higher than the one generally used $\left(1 \times 10^{5}\right.$ spermatozoa/ml $)$ in order to maximally reduce the interval of sperm penetration into oocytes by working with a shorter time of co-incubation $(2 \mathrm{~h})$, according to Coy et al. (1993). Such a high sperm concentration produced an elevated incidence of polyspermy and therefore a low percentage of monospermic zygotes; nevertheless, with these conditions we were able to synchronize the time of sperm penetration and therefore the beginning of fertilization in order to obtain the most similar kinetics of PN development among the zygotes.

After the co-incubation with spermatozoa the mature oocytes were transferred into fresh fertilization medium and incubated for a further $10-12 \mathrm{~h}$ to reach the PN stage.

In order to assess the potential role of HDAC in the regulation of histone acetylation, a specific inhibitor of deacetylase enzyme, trichostatin A (TSA; $330 \mathrm{nmol} / \mathrm{l}$; Sigma Chemical Co.), was used. With this aim a small group of in vivo matured oocytes were exposed to TSA during the whole IVF interval.

At the end of incubation all oocytes were briefly incubated in Tyrode's solution and transferred into $0.1 \%(\mathrm{w} / \mathrm{v})$ pronase to remove the zonae pellucida and then fixed in acetic acid/ethanol (1:3) for 34-48 $\mathrm{h}$ and stained with lacmoid (Sigma).

\section{Evaluation of events after IVF}

Lacmoid-stained IVF oocytes were observed under a phasecontrast microscope in order to evaluate the fertilization rate, the percentage of monospermic oocytes and their ability to develop male PN. Oocytes were classified as fertilized when one or more spermatozoa had entered the oocyte and monospermic when a single sperm head (condensed or decondensed) or one male PN (identified by the sperm tail remnant nearby) was present within the ooplasm. Monospermic oocytes were classified in different developmental categories (PN1 to PN5) according to Laurincik et al. 
(1994). In category PN1 the oocytes are completely penetrated by the sperm and the second meiotic division has resumed; in category PN2 the decondensation of chromosomes starts, the sperm tail is detached and the second polar body is extruded; in category PN3 the oocytes are characterized by further decondensation and by the appearance of the nuclear envelope. All these categories of oocytes were discarded and slides with monospermic oocytes belonging to category PN4-PN5, which are zygotes presenting spherical male and female $\mathrm{PN}$ with a complete nuclear envelope and maximum size close together, were selected and further analyzed for DNA methylation, histone $\mathrm{H} 4$ acetylation and HDAC distribution. Monospermic oocytes and the relative position of male and female PN were schematically noted and marked on each slide at the end of the morphological evaluation in order to identify, during the subsequent immunofluorescence analysis, the position of male PN.

\section{Immunofluorescence protocol}

Indirect immunofluorescence was carried out to evaluate and compare the pattern of DNA methylation, histone $\mathrm{H} 4$ acetylation and the subcellular localization of HDAC-1, HDAC-2 and HDAC-3 in PN4-PN5 zygotes obtained from in vivo, in vitro or in vivo/vitro matured oocytes.

With this aim the slides containing marked zygotes were washed with $0.05 \%(\mathrm{v} / \mathrm{v})$ Tween-20 in PBS, fixed again for $2 \mathrm{~h}$ in $4 \%(\mathrm{w} / \mathrm{v})$ paraformaldehyde in PBS and permeabilized with $0.2 \%(\mathrm{v} / \mathrm{v})$ Triton $\mathrm{X}-100$ in PBS for $1 \mathrm{~h}$ at room temperature.

For the detection of 5-methyl cytosine, the slides were further incubated for $2 \mathrm{~h}$ with $2 \mathrm{~mol} \mathrm{HCl} / \mathrm{l}$ at room temperature for DNA denaturation and subsequently neutralized for 20 min with $100 \mathrm{mmol}$ Tris $\mathrm{HCl} / \mathrm{l}$ buffer $(\mathrm{pH} \mathrm{8.5)}$. After washing with $0.5 \%(\mathrm{v} / \mathrm{v})$ Tween-20 in PBS, the zygotes were blocked for $2 \mathrm{~h}$ at room temperature in $1 \%$ (w/v) BSA/0.05\% (v/v) Tween-20/20\% (v/v) goat serum and then incubated at $4{ }^{\circ} \mathrm{C}$ overnight in the presence of a specific primary antibody (mouse monoclonal anti5-methyl cytosine; Eurogentec, Seraing, Belgium) diluted $1: 500$ in $1 \%(\mathrm{w} / \mathrm{v})$ BSA $/ 0.05 \%(\mathrm{v} / \mathrm{v})$ Tween-20 solution. The primary antibody was detected by a secondary antibody coupled with Cy3 (1:400 dilution; Molecular Probes, Eugene, OR, USA).

For the detection of hyperacetylated histone $\mathrm{H} 4$ and HDAC isoforms, the zygotes were incubated with the antihyperacetylated histone $\mathrm{H} 4$ (rabbit polyclonal, 1:300 dilution; Upstate Biotechnology, New York, NY, USA), anti-HDAC-1, anti-HDAC-2 and anti-HDAC-3 (rabbit polyclonal, 1:200 dilution; Santa Cruz Biotechnology, Santa Cruz, CA, USA) primary antibodies. Anti-rabbit gamma globulin-Cy3 coupled (1:400 dilution; Molecular Probes) was then used as secondary antibodies. In experiments carried out on zygotes obtained from in vivo matured oocytes, negative control samples, in which the primary antibody was omitted, were also evaluated.
DNA was finally stained with $1 \mu \mathrm{mol}$ SYBR $14 / \mathrm{l}$ (Molecular Probes).

\section{Laser scanning confocal microscopy}

Immunostained zygotes were observed with a Bio-Rad (Hercules, CA, USA) laser scanning confocal microscope (Radiance 2000 IK-2), equipped with a krypton/argon ion laser. The system was analyzed on an inverted microscope (Zeiss Axiovert) equipped with a plan-apochromat oil immersion objective $63 \times$ magnification /1.4 numerical aperture. The analysis of immunostained and DNA-labelled zygotes was simultaneously carried out by using the visible lines of excitation of $488 \mathrm{~nm}$ and $568 \mathrm{~nm}$ respectively, and a dichroic filter (560LP; Bio Rad). Digital optical sections were obtained by scanning a z-series of $0.2 \mu \mathrm{m}$ slices throughout the planes of focus containing maternal and paternal PN; the sections were later projected to obtain a three-dimensional reconstruction and all the images were exported as 8 bit-tagged image file format files.

According to Beaujean et al. (2004b, 2004c), for quantitative measurements of the fluorescence emitted by each PN we merged the $\mathrm{z}$-series collected with the LaserSharp software (Bio-Rad) to produce a two-dimensional image showing the staining pattern and the total fluorescence intensity of the two PN of the zygote analysed. The correction from background was obtained by subtracting the mean intensity of the cytoplasmic area to the whole image. Each PN was outlined manually in order to measure PN fluorescence intensity; the total fluorescence intensity emitted from each PN was measured using LaserPix software (Bio-Rad) and the values compared between male and female PN.

\section{Statistical analysis}

All experiments comprised six replicates involving a total of 348 in vivo matured oocytes, 564 IVM and 229 in vivo/vitro matured oocytes. All data were tested for normal distribution and then were analyzed by the Chi Square test and were considered significant at $P<0.01$.

\section{Results}

\section{Sperm penetration after IVF of oocytes matured in vivo, in vitro or in vivo/vitro}

Fertilization rate after IVF, expressed as the percentage of oocytes that were penetrated by at least one sperm, was not affected by maturation with values of $62 \%(n=348)$, $59 \%(n=564)$ and $56 \%(n=229)$ for in vivo matured, IVM and in vivo/vitro matured oocytes respectively (Table 1). By contrast, in vivo $(78 \% ; n=240)$ and in vivo/vitro oocytes $(82 \% ; n=128)$ showed a higher percentage of monospermic fertilization than IVM oocytes $(36 \%$, $n=333 ; \quad P<0.01$; Table 1). In addition, whereas the majority of monospermic zygotes obtained from in vivo $(90 \% ; n=187)$ and in vivo/vitro matured oocytes $(85 \%$; 


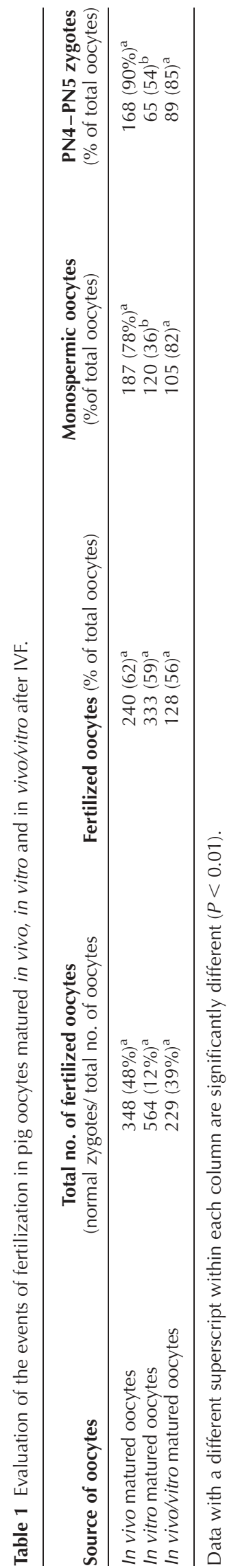

$n=105)$ developed the late PN stage (PN4-PN5) 12-14 h after IVF, the same stage of PN development was recorded only in $54 \%(n=120 ; P<0.01)$ of IVM oocytes (Table 1$)$.

\section{Whole DNA methylation in zygotes obtained from in vivo, in vitro or in vivo/vitro matured oocytes}

The analysis of DNA global methylation patterns showed that, in the majority of PN4-PN5 zygotes derived from in vivo and in vivo/vitro matured oocytes, the two PN displayed different fluorescence intensity (Fig. 1B). In fact, $80 \%(n=25)$ and $73 \%(n=26)$ of the PN4-PN5 zygotes respectively showed a demethylated male $\mathrm{PN}$ that resulted in about $38 \%$ less fluorescent $(77.66$; S.D. $=22.90)$ than female ones $(125.20 ;$ S.D. $=16.84)$. In the remaining zygotes, a similar fluorescence intensity (difference $<10 \%$ ) in the male $(114.70 ;$ S.D. $=15.52)$ and female $(123.78$; S.D. $=20.21)$ PN was recorded (Fig. 1E).

PN4-PN5 zygotes derived from IVM oocytes showed male $\mathrm{PN}$ hypomethylated relative to female $\mathrm{PN}$ only in $40 \%$ of cells analyzed $(n=20 ; P<0.01$; Table 2$)$, whereas in the remaining zygotes $\mathrm{PN}$ displayed similar levels of DNA methylation.

\section{Histone $\mathrm{H} 4$ acetylation in zygotes obtained from in vivo, in vitro or in vivo/vitro matured oocytes}

Male and female PN exhibited different histone acetylation levels in most of the PN4-PN5 zygotes derived from oocytes matured in vivo. Eighty-two per cent of these cells $(n=35$; Table 2$)$ presented, in fact, the male PN about 29\% more acetylated than the female one (114.85; S.D. $=25.44$ and 81.54; S.D. $=15.22$ respectively). Besides the different fluorescence intensity, the comparative analysis of chromatin histone acetylation in the two PN by laser scanning confocal microscopy revealed a different pattern of distribution of fluorescent signal between PN. Clusters of acetylated chromatin were irregularly distributed throughout male PN, whereas fluorescence was more homogeneously spread throughout female PN (Fig. 2B). Maturation affects the ability of the oocyte to differentially acetylate male and female histones. Zygotes derived from IVM oocytes showed the male PN more acetylated than the female one only in $38 \%$ of the cases $(n=26 ; P<0.01$; Table 2). Moreover $28 \%$ of zygotes derived from IVM oocytes had a male PN with the acetylated chromatin polarized in peripheral nuclear districts (Fig. 2D) while the remaining showed a similar pattern of fluorescence distribution and similar levels (difference $<10 \%$ ) of histone acetylation in female (108.79; S.D. $=24.32$ ) and male (115.53; s.D. = 16.36) PN (Fig. 2E).

The zygotes derived from in vivo/vitro matured oocytes had a satisfactory ability to remodel paternal chromatin since the male $\mathrm{PN}$ was hyperacetylated relative to the female one in $76 \%$ of cases $(n=34$; Table 2$)$, a percentage similar to that recorded in zygotes obtained from in vivo matured oocytes $(P>0.01)$. Moreover, the fluorescence pattern of hyperacetylated chromatin in male PN 

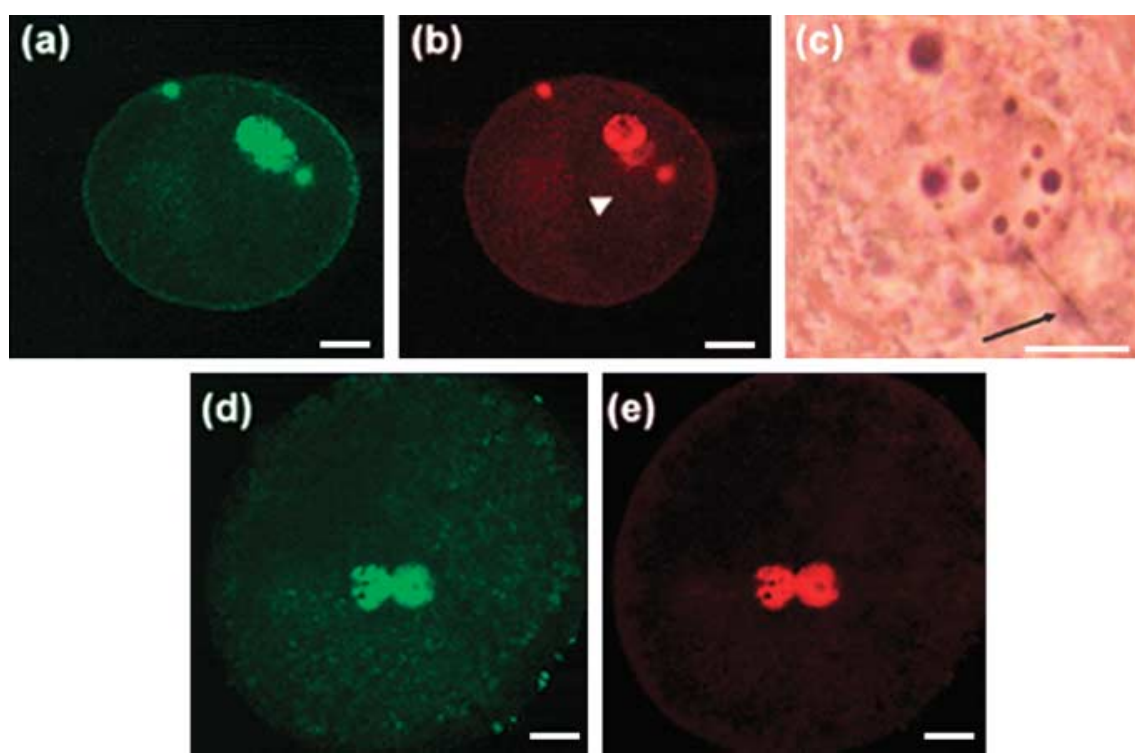

Figure 1 Confocal laser scanning micrographs of whole DNA methylation in pig zygotes at $12-14 \mathrm{~h}$ after IVF. (a, b and c) Representative images of zygote at the PN4-PN5 stage produced from in vivo matured oocyte that shows a demethylated male PN. (a) Green fluorescence indicates cell DNA stained with SYBR 14. Scale bar represents $20 \mu \mathrm{m}$. (b) Methylated DNA in male and female PN immunostained with anti-5-methyl cytosine antibody and Cy3-conjugated anti-mouse IgG. Scale bar represents $20 \mu \mathrm{m}$. The arrowhead indicates the position of the demethylated male PN, as confirmed (c) by the presence of sperm tail nearby (arrow). Scale bar represents $10 \mu \mathrm{m}$. (d and e) Example of zygote produced from an IVM oocyte showing similar levels of DNA methylation in male and female PN. Scale bars represent $20 \mu \mathrm{m}$. (d) Visualization of pronuclear DNA stained by SYBR 14. (e) Anti-5-methyl cytosine immunofluorescence of methylated DNA in male and female PN.

reproduced that recorded in zygotes obtained in physiological conditions (data not shown).

\section{Subcellular distribution of HDAC isoforms in zygotes produced from in vivo, in vitro or in vivo/vitro matured oocytes}

Experiments were carried out to investigate the distribution of HDAC-1, HDAC-2 and HDAC-3 in the different groups of PN4-PN5 zygotes, in order to understand the reasons for the different patterns of acetylation/methylation recorded in male and female PN. Preliminary analysis of the enzyme localization carried out in zygotes derived from in vivo matured oocytes showed that HDAC-1 ( $n=15$; Fig. 3 ) and HDAC-3 ( $n=12$; data not shown) isoforms were exclusively localized in the cytoplasm, suggesting that these isoforms are not involved in chromatin remodelling at the $\mathrm{PN}$ zygote stage. By contrast, HDAC2 was clearly localized within the PN (Fig. 4), thus suggesting a direct contribution of this isoform of the enzyme to post-fertilization chromatin remodelling. Consistent with the recorded acetylation patterns, fluorescence intensity was not similar between the two PN (Fig. 4B) and, in $89 \%(n=38)$ of the zygotes obtained from in vivo matured oocytes, the male PN displayed about 33\% lower fluorescence intensity (79.41; S.D. $=18.83)$ than the female one $(118.52$; S.D. $=32.54)$. A similar asymmetric fluorescence between the two PN was also recorded in $87 \%$ $(n=29 ; P>0.01)$ of zygotes obtained from in vivo/vitro matured oocytes, while only in $44 \%(n=19 ; P<0.01)$ of the zygotes obtained from IVM/IVF oocytes (Table 2 ). In all groups, the remaining zygotes displayed the two PN with similar fluorescence intensity (difference $<10 \%$ ).

\section{Role of HDAC-2 in PN chromatin remodelling}

Following TSA treatment during the IVF interval, $78 \%$ of zygotes that developed late PN stages (PN4-PN5, $n=16$; $P<0.01)$ lost the asymmetric level of acetylation between male and female PN, and female PN presented values of

Table 2 DNA methylation, histone H4 acetylation and HDAC-2 distribution in PN4-PN5 zygotes obtained from pig oocytes matured in vivo, in vitro, or in vivo/vitro

\begin{tabular}{|c|c|c|c|}
\hline Source of oocytes & $\begin{array}{c}\text { No. (\%) of zygotes with demethylated } \\
\text { male PN }\end{array}$ & $\begin{array}{c}\text { No. (\%) of zygotes with hyperacetylated } \\
\text { male PN }\end{array}$ & $\begin{array}{l}\text { No. }(\%) \text { of zygotes with lower } \\
\text { level of HDAC-2 in male PN }\end{array}$ \\
\hline In vivo matured oocytes & $25(8 \%)^{\mathrm{a}}$ & $35(82)^{\mathrm{a}}$ & $38(89)^{a}$ \\
\hline In vitro matured oocytes & $20(40 \%)^{b}$ & $26(38 \%)^{b}$ & $19(44)^{\mathrm{b}}$ \\
\hline In vivo/vitro matured oocytes & $26(73 \%)^{a}$ & $34(76)^{\mathrm{a}}$ & $29(87)^{\mathrm{a}}$ \\
\hline
\end{tabular}

Data with a different superscript within each column are significantly different $(P<0.01)$. 

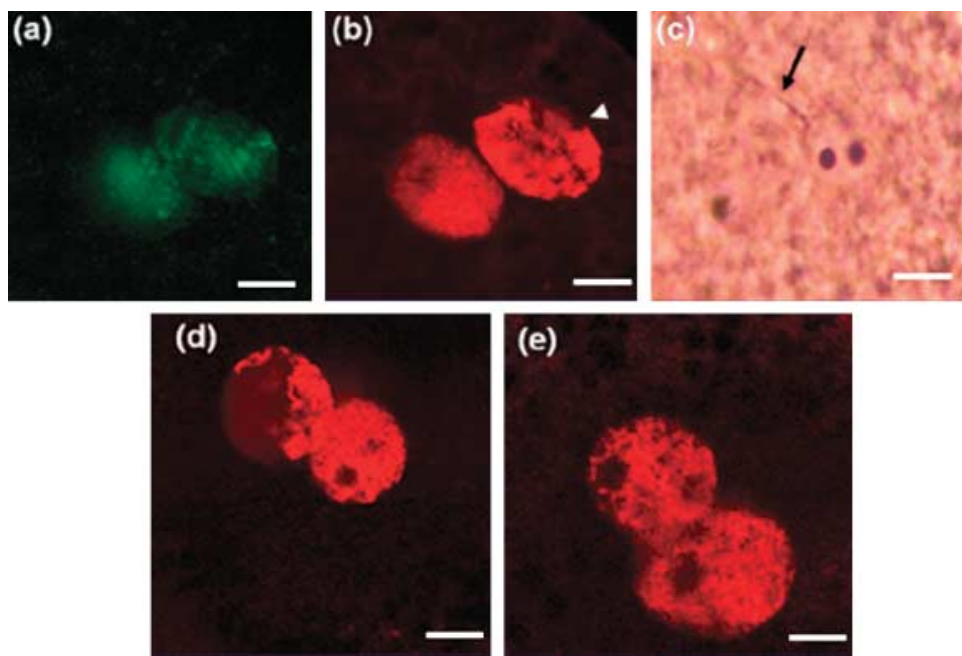

Figure 2 Pattern of histone $\mathrm{H} 4$ acetylation in pig zygotes at 12-14 h after IVF. (a, b and c) Representative images of zygote produced from in vivo matured oocyte at the PN4-PN5 stage that shows differential histone $\mathrm{H} 4$ acetylation between the two PN. Scale bars represent $10 \mu \mathrm{m}$. (a) Visualization of PN DNA stained by SYBR 14. (b) Comparative analysis between parental PN by confocal laser microscopy highlights a difference in both fluorescence intensity and pattern of fluorescence distribution obtained by zygote immunostaining with anti-hyperacetylated histone $\mathrm{H} 4$ antibody and Cy3-conjugated anti-rabbit IgG. Male PN (arrowhead) is characterized by a higher level of acetylation than female PN and its acetylated chromatin is organized in clusters rather than homogeneously distributed within the PN as observed in the female one.

(c) Visualization by phase contrast microscope of the sperm tail (arrow) close to male PN following staining with lacmoid. (d and e) Two examples of abnormal distribution of acetylated chromatin in zygotes produced from IVM oocytes. Scale bars represent $10 \mu \mathrm{m}$. (d) Zygote showing male PN with acetylated chromatin polarized in peripheral districts. (e) Zygote showing male and female PN with similar levels of histone H4 acetylation.

fluorescence intensity similar to that recorded in male PN (difference of fluorescence intensity $<10 \%$; 117.85; S.D. $=33.45$ and $122.54 ;$ S.D. $=27.04$ respectively; Fig. 5). In the remaining zygotes, female $\mathrm{PN}$ maintained the condition of reduced chromatin histone acetylation as compared with male PN.

\section{Discussion}

The present paper addresses the issue of the developmental competence of mature oocytes in the pig by focussing on the sequential steps that transform the penetrated sperm into male chromatin structurally and molecularly rearranged for integrating with female chromatin and
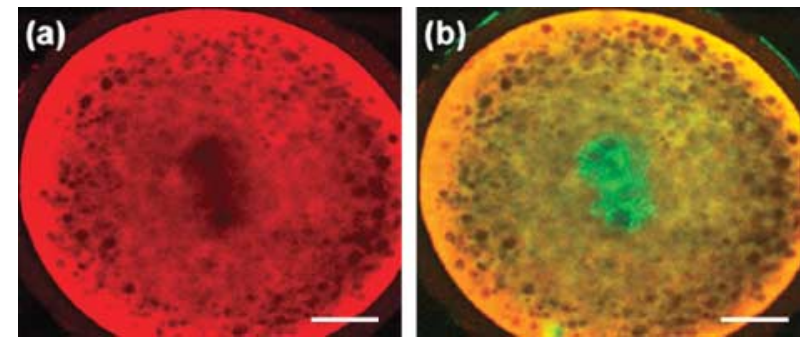

Figure 3 Subcellular distribution of HDAC-1 in pig zygote produced from in vivo matured oocyte double stained with immunofluorescence (anti-HDAC-1 antibody and Cy3-conjugated anti-rabbit IgG) and SYBR 14. Scale bars represent $20 \mu \mathrm{m}$. (a) HDAC-1 isoform is localized in the ooplasm of the zygote, outside the two PN.

(b) Merged image that simultaneously visualizes PN DNA stained by SYBR 14 and HDAC-1 distribution.
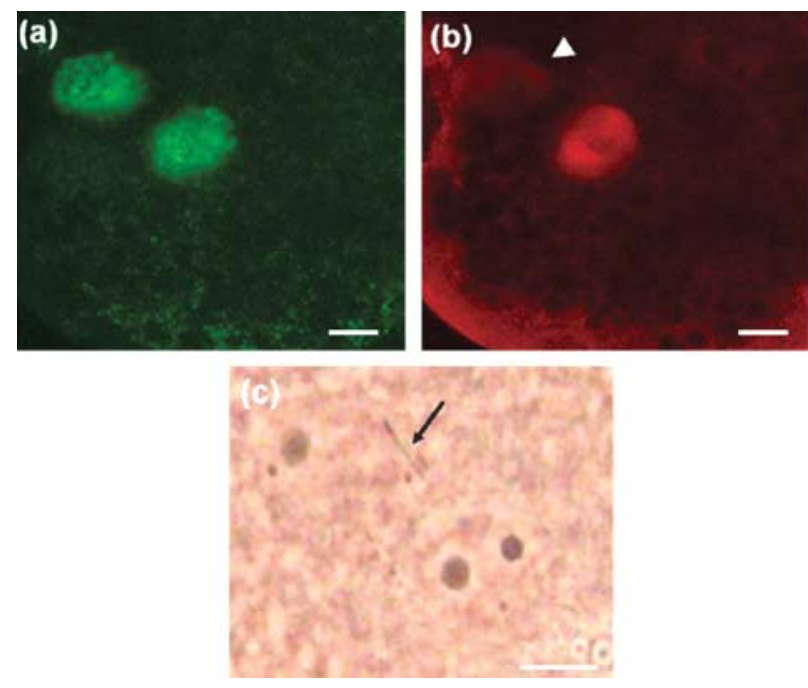

Figure 4 Subcellular distribution of HDAC-2 in pig zygote at $12-14 \mathrm{~h}$ after IVF. (a, b and c) Representative images of zygote at the PN4PN5 stage produced from in vivo matured oocyte that shows differential HDAC-2 levels between the two PN. Scale bars represent $10 \mu \mathrm{m}$. (a) Visualization of PN DNA stained by SYBR 14. (b) Visualization of HDAC-2 in male and female PN following immunostaining with the anti-HDAC-2 antibody and Cy3-conjugated anti-rabbit lgG. This isoform of the enzyme is localized inside PN and male PN (arrowhead) is characterized by a lower level of fluorescence as compared with the female one. (c) Visualization by phase contrast microscope of the sperm tail (arrow) close to male PN following zygote staining with lacmoid. 

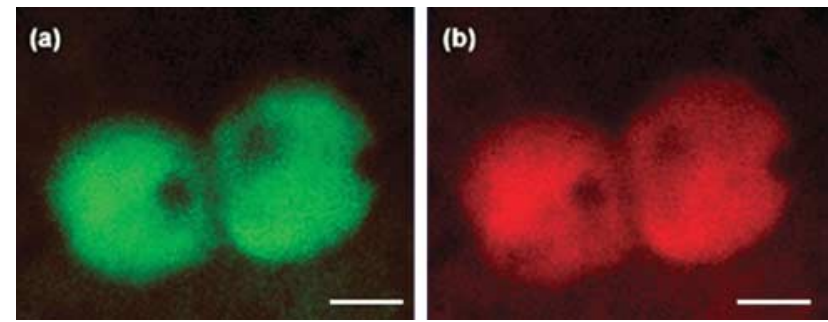

Figure 5 Pattern of histone $\mathrm{H} 4$ acetylation in pig zygote obtained from an in vivo matured oocyte exposed to TSA during the IVF interval. (a) Visualization of PN DNA stained by SYBR 14. Scale bar represents $10 \mu \mathrm{m}$. (b) Following the inactivation of deacetylating enzyme, male and female PN present similar levels of chromatin histone $\mathrm{H} 4$ acetylation and within the male PN the acetylated chromatin is homogeneously distributed instead of being organized in clusters. Scale bar represents $10 \mu \mathrm{m}$.

supporting full embryo development. All these changes rely exclusively on oocyte resources and hence their analysis might be useful for assessing the degree of oocyte maturation. The strategy adopted to carry out this study involved comparison between oocytes matured under physiological conditions, which have presumably acquired all that is required for a proper sperm nucleus remodelling and IVM oocytes which, despite the satisfactory results so far obtained (Mattioli et al. 1989, Prather \& Day 1998, Hunter 2000, Abeydeera 2001, Nagai 2001, Niemann \& Rath 2001), are still unable to guarantee normal developmental competence. For this reason, IVM oocytes may be a useful model to reveal the crucial functions that are conditioned by the process of maturation (Mattioli 1992, Sun \& Nagai 2003, Bjerregaard et al. 2004).

The results presented here have confirmed that the ability of the oocyte to form male PN is strictly related to the degree of maturation, as in vivo matured oocytes were able to support the sperm-PN transition in the majority of the cases, while such a transformation was completed only in a small proportion of IVM eggs. This finding is consistent with the results presented by other authors (Laurincik et al. 1994) and confirms our previous investigations (Mattioli et al. 1988a, 1998b) which pointed to male PN formation as a key parameter to test the goodness of IVM procedures. Moreover, the analysis of in vitro experiments suggests that the acquisition of sperm remodelling competence follows a stepwise pattern. In fact, sperm chromatin decondensation, a first preliminary phase of sperm remodelling involving the reduction of protamine disulfide bonds, represents a primary level of competence since only some of the eggs capable of decondensing penetrated sperm can later support its transformation into male PN (Mattioli et al. 1988a, 1998b, Sun \& Nagai 2003). In addition, we have demonstrated, in keeping with this finding, that only some of the zygotes that reached the PN4-PN5 stage can, subsequently, operate the physiological epigenetic chromatin rearrangement of the paternal genome. The percentage of PN4-PN5 zygotes obtained in vitro that we analysed in our experiments was lower compared with the percentage of $\mathrm{PN}$ produced in vitro by other authors, but this could be because of the IVF procedure utilized, where a high concentration of spermatozoa was used to fertilize within a short window of IVF in order to synchronize the beginning of the fertilization process. In contrast, the incidence of normospermic fertilization cannot be deduced from the percentage of IVM/IVF zygotes that reached the blastocyst stage in vitro, since clear evidence has demonstrated that, in the pig, a percentage of embryos reach this stage of development even following polyspermic fertilization (Han et al. 1999, Kikuchi 2004).

Under physiological conditions, DNA methylation and histone acetylation are asymmetrically arranged in male and female $\mathrm{PN}$ in the pig. The active demethylation of sperm genome observed during the formation of a functional PN appeared to be similar to that described originally in mouse zygotes (Mayer et al. 2000, Oswald et al. 2000, Santos et al. 2002) and, more recently, in rat, bovine (Dean et al. 2001) and human zygotes (Beaujean et al. 2004a), while histone hyperacetylation recorded in male PN before singamy seems to follow a different kinetic from that described in the mouse model (Adenot et al. 1997). Such a species difference in paternal chromatin rearrangement is not surprising, since male PN demethylation seems not to be an obligatory requirement at the zygote stage in sheep and rabbit (Beaujean et al. 2004b, Shi et al. 2004) and re-methylation occurring in a number of species at blastocyst stage was not recorded in sheep embryos (Young \& Beaujean 2004).

Post-fertilization genome remodelling therefore does not follow a conserved programme and epigenetic remodelling patterns cannot be automatically extended from one species to others.

In general, both maternal and paternal DNA are heavily methylated at the time of fertilization but a few hours later the male PN has undergone a marked demethylation. This action, which does not involve female $\mathrm{PN}$ at all, is quite surprising as both maternal and paternal chromatins are embedded in the same intracellular environment, the ooplasm, but DNA demethylation operates selectively towards paternal chromatin. As no DNA replication occurs during early PN development, zygotes have provided the first strong evidence of the existence of an active demethylation (Dean et al. 2001). In this context, the persistence of genome imprinting marks (Sapienza et al. 1987), based on cytosine methylation, emphasizes the complexity and selectivity of this process and its potential influence on embryo/fetal development.

In keeping with the changes in DNA methylation, we have here described, in the pig, higher levels of histone $\mathrm{H} 4$ acetylation in male PN than in the female one, thus confirming the inverse relationship between DNA methylation and histone acetylation proposed by a number of authors (Cervoni \& Szyf 2001, Geiman \& Robertson 2002, Lusser 2002) as a model to interpret genome regulation. 
The influence of maturation on the competence of the oocyte to carry out a proper epigenetic remodelling of parental chromatins becomes evident from the results obtained when PN methylation and acetylation were recorded in zygotes from in vivo matured oocytes in comparison with those recorded in zygotes from IVM oocytes. While, in fact, the asymmetry between male and female PN occurs in approximately $80 \%$ of in vivo matured and IVF oocytes, only $40 \%$ of IVM/IVF zygotes presented this, presumably, adequate chromatin rearrangement. At present, we do not know exactly what may be the functional significance of the absence of differential PN remodelling but it certainly represents a deviation from what occurs under physiological conditions. Moreover, we have here shown that the ability to impose genome-wide epigenetic changes can be guaranteed in the zygotes when the first phase of maturation is carried out in vivo, after which meiosis can be completed in vitro without compromising the ability to perform DNA methylation and histone acetylation during the post-fertilization interval. This finding, apart from the possible physiological implication for understanding the events that characterize the process of oocyte maturation (McLay \& Clarke 1997), may have an important impact in assisted reproduction where IVM is assuming a growing relevance and the use of oocytes committed to mature in vivo could be a promising strategy.

Chromatin remodelling depends on the synthesis of specific enzymes, their activation and, finally, their nucleus-cytoplasm distribution. To focus this issue, bearing in mind that the presence of methyl residues on DNA attracts a family of proteins that in turn fix HDAC on the chromatin (Fuks et al. 2003) and that the regulation of HDAC activity involves its nucleus-cytoplasm distribution (De Ruijter et al. 2003), the intracellular HDAC location was investigated. The enzyme is present with different isoforms (De Ruijter et al. 2003) but their distribution indicates that isoform 2, localized inside the PN, is the form that contributes to genome remodelling, while other isoforms studied, essentially concentrated in the cytoplasm, do not appear to play a role in chromatin rearrangement at the time of early embryo development. Although present in both PN, the HDAC-2 isoform is more concentrated in female $\mathrm{PN}$, thus providing a potentially convincing explanation for the lower histone acetylation recorded in this chromatin. Histone acetylation may result, however, from the action of two opposite enzymes, histone acetyl-transferase and HDAC, but the observation that TSA, a potent HDAC inhibitor, virtually eliminated $\mathrm{PN}$ acetylation asymmetry points to the deacetylating enzyme as the major factor responsible for the differential $\mathrm{PN}$ acetylation. When nucleus-cytoplasm distribution of HDAC was investigated in zygotes from IVM oocytes, where asymmetrical PN acetylation was recorded in a low proportion of cells, in parallel a similar low percentage of zygotes displayed the asymmetrical distribution of the enzyme between male and female PN. This data further confirmed the major role that HDAC plays in modulating histone acetylation under physiological conditions.

Interestingly enough, a small proportion of zygotes obtained following in vivo maturation did not exhibit the PN asymmetry and male and female chromatins could reach singamy having similar levels of DNA methylation and histone $\mathrm{H} 4$ acetylation.

If remodelling competence is conditioned by the process of maturation, it is likely that whenever maturation occurs under abnormal conditions, such as those following hormonal hyperstimulation (Barton et al. 2001, Shi \& Haaf 2002) or under general bad nutritional conditions (Wu et al. 2004), this functional competence may not be completely achieved, as we recorded in vitro, thus compromising embryo-fetal development.

\section{Acknowledgements}

This work was supported by cofinanziamento MIUR Es. Fin. 2001. The authors declare that there is no conflict of interest that would prejudice the impartiality of this scientific work.

\section{References}

Abeydeera LR 2001 In vitro fertilization and embryo development in pigs. Reproduction 58 (Suppl) 159-173.

Adenot PG, Szollosi MS, Geze M, Renard JP \& Debey P 1991 Dynamics of paternal chromatin changes in live one-cell mouse embryo after natural fertilization. Molecular Reproduction and Development 28 23-24.

Adenot PG, Mercier Y, Renard JP \& Thompson EM 1997 Differential $\mathrm{H} 4$ acetylation of paternal and maternal chromatin precedes DNA replication and differential transcriptional activity in pronuclei of 1-cell mouse embryos. Development 124 4615-4625.

Barboni B \& Mattioli M 1996 Oocyte maturation involves important changes required for activation competence. Reproduction in Domestic Animals 31 589-594.

Barboni B, Mattioli M \& Seren E 1995 Influence of progesterone on boar sperm capacitation. Journal of Endocrinology 144 13-18.

Barton SC, Arney KL, Shi W, Niveleau A, Fundele R, Surani MA \& Haaf T 2001 Genome-wide methylation patterns in normal and uniparental early mouse embryos. Human Molecular Genetics 10 2983-2987.

Beaujean N, Hartshorne G, Cavilla J, Taylor J, Gardner J, Wilmut I, Meehan R \& Young L 2004a Non-conservation of mammalian preimplantation methylation dynamics. Current Biology 14 R266-R267.

Beaujean N, Taylor J, Gardner J, Wilmut I, Meehan R \& Young L $2004 b$ Effect of limited DNA methylation reprogramming in the normal sheep embryo on somatic cell nuclear transfer. Biology of Reproduction 71 185-193.

Beaujean N, Taylor JE, McGarry M, Gardner JO, Wilmut I, Loi P, Ptak G, Galli C, Lazzari G, Bird A, Young LE \& Meehan RR 2004c The effect of interspecific oocytes on demethylation of sperm DNA. PNAS 101 7636-7640.

Bjerregaard B, Wrenzycki C, Strejcek F, Laurincik J, Holm P, Ochs RL, Rosenkranz C, Callesen H, Rath D, Niemann H \& MaddoxHyttel P 2004 Expression of nucleolar-related proteins in porcine preimplantation embryos produced in vivo and in vitro. Biology of Reproduction 70 867-876.

Borsuk E \& Manka R 1988 Behavior of sperm nuclei in intact and bisected metaphase II mouse oocytes fertilized in the presence of colcemid. Gamete Research 20 365-376. 
Carroll J, Swann K, Whittingham \& Whitaker M 1994 Spatiotemporal dynamics of intracellular $[\mathrm{Ca} 2+]$ oscillations during the growth and meiotic maturation of mouse oocytes. Development $1203507-3517$.

Cervoni N \& Szyf M 2001 Demethylase activity is directed by histone acetylation. Journal of Biological Chemistry 276 40778-40787.

Coy $\mathbf{P}$, Martìnez E, Ruiz S, Vàzquez JM, Roca J, Matas C \& Pellicer MT 1993 In vitro fertilization of pig oocytes after different coincubation intervals. Theriogenology 39 1201-1208.

Cran D \& Cheng W 1985 Changes in cortical granules during porcine oocyte maturation. Gamete Research 11 311-319.

Dean W, Santos F, Stojkovic M, Zakhartchenko V, Walter J, Wolf E \& Reik W 2001 Conservation of methylation reprogramming in mammalian development: aberrant reprogramming in cloned embryos. PNAS 98 13734-13738.

De Ruijter AJM, Van Gennip AH, Caron HN, Kemp S \& van Kuilenburg ABP 2003 Histone deacetylases (HDACs): characterization of the classical HDAC family. Biochemical Journal 370 737-749.

Ducibella T, Duffy P, Reindollar R \& Su B 1990 Changes in the distribution of mouse oocyte cortical granules and ability to undergo the cortical reaction during gonadotropin-stimulated meiotic maturation and aging in vivo. Biology of Reproduction 43 870-876.

Fuks F, Hurd PJ, Wolf D, Nan X, Bird AP \& Kouzarides T 2003 The methyl-CpG-binding protein MeCP2 links DNA methylation to histone methylation. Journal of Biological Chemistry 278 4035-4040.

Galeati G, Modina S, Lauria A \& Mattioli M 1991 Follicle somatic cells influence pig oocyte penetrability and cortical granule distribution. Molecular Reproduction and Development 29 40-46.

Geiman TM \& Robertson KD 2002 Chromatin remodelling, histone modifications, and DNA methylation - how does it all fit together? Journal of Cellular Biochemistry 87 117-125.

Han YM, Abeydeera LR, Kim JH, Moon HB, Cabot RA, Day BN \& Prather RS 1999 Growth retardation of inner cell mass cells in polyspermic oocytes matured and fertilized in vitro. Biology of Reproduction 60 1110-1113.

Hunter MG 2000 Oocyte maturation and ovum quality in pigs. Reviews of Reproduction 5 122-130.

Kikuchi K 2004 Developmental competence of porcine blastocysts produced in vitro. Journal of Reproduction and Development $\mathbf{5 0}$ 21-28.

Kopecny V \& Pavlok A 1975 Autoradiographic study of mouse spermatozoan arginine-rich nuclear protein in fertilization. Journal of Experimental Zoology 191 85-96.

Kramer JA \& Krawetz SA 1997 RNA in spermatozoa: implications for the alternative haploid genome. Molecular Human Reproduction 3 $473-478$

Laurincik J, Rath D \& Niemann H 1994 Differences in pronucleus formation and first cleavage following in vitro fertilization between pig oocytes matured in vivo and in vitro. Journal of Reproduction and Fertility 102 277-284.

Lusser A 2002 Acetylated, methylated, remodelled: chromatin states for gene regulation. Current Opinion in Plant Biology 5 437-443.

McEvoy TG, Ashworth CJ, Rooke JA \& Sinclair KD 2003 Consequences of manipulating gametes and embryos of ruminant species. Reproduction 61 (Suppl) 167-182.

McLay DW \& Clarke HJ 1997 The ability to organize sperm DNA into functional chromatin is acquired during meiotic maturation in murine oocytes. Developmental Biology 186 73-84.

McLay DW \& Clarke HJ 2003 Remodelling the paternal chromatin at fertilization in mammals. Reproduction 125 625-633.

Mattioli M 1992 Biology of oocyte maturation. In Embryonic Development and Manipulation in Animal Production, pp 17-28. Eds A Lauria \& F Gandolfi. London: Portland Press.

Mattioli M, Galeati G, Bacci ML \& Seren E 1988a Follicular factors influence oocytes fertilizability by modulating the intercellular cooperation between cumulus cells and oocyte. Gamete Research $21223-232$.
Mattioli M, Galeati G \& Seren E 1988b Effect of follicle somatic cells during pig oocyte maturation on egg penetrability and male pronucleus formation. Gamete Research 20 177-183.

Mattioli M, Bacci ML, Galeati G \& Seren E 1989 Developmental competence of pig oocytes matured and fertilized in vitro. Theriogenology 31 1201-1207.

Mattioli M, Barboni B \& Lucidi P 1996 Oxygen tension throughout maturation affects oocyte GSH content and the ability to transform penetrated spermatozoa into male pronuclei. Biology of Reproduction $\mathbf{5 4}$ (Suppl) 169.

Mayer W, Niveleau A, Walter J, Fundele R \& Haaf T 2000 Demethylation of the zygotic paternal genome. Nature 403 501-502.

Mehlmann LM \& Kline D 1994 Regulation of intracellular calcium in the mouse egg: calcium release in response to sperm or inositol trisphosphate is enhanced after meiotic maturation. Biology of Reproduction 51 1088-1098.

Mehlmann LM, Terasaki M, Jaffe LA \& Kline D 1995 Reorganization of the endoplasmic reticulum during meiotic maturation of the mouse oocyte. Developmental Biology 170 607-615.

Nagai T 2001 The improvement of in vitro maturation systems for bovine and porcine oocytes. Theriogenology 55 1291-1301.

Niemann H \& Wrenzycki C 2000 Alterations of expression of developmentally important genes in preimplantation bovine embryos by in vitro culture conditions: implications for subsequent development. Theriogenology 53 21-34.

Niemann H \& Rath D 2001 Progress in reproductive biotechnology in swine. Theriogenology $\mathbf{5 6} 1291-1304$.

Niemann H, Wrenzycki C, Lucas-Hahn A, Brambrink T, Kues WA \& Carnwath JW 2002 Gene expression patterns in bovine in-vitro produced and nuclear transfer-derived embryos and their implications for early development. Cloning Stem Cells 4 29-38.

Oswald J, Engemann S, Lane N, Mayer W, Olek A, Fundele R, Dean W, Reik W \& Walter J 2000 Active demethylation of the paternal genome in the mouse zygote. Current Biology 10 475-478.

Prather RS \& Day BN 1998 Practical considerations for the in vitro production of pig embryos. Theriogenology $14923-32$.

Reik W, Dean W \& Walter J 2001 Epigenetic reprogramming in mammalian development. Science 293 1089-1093.

Santos F, Hendrich B, Reik W \& Dean W 2002 Dynamic reprogramming of DNA methylation in the early mouse embryo. Developmental Biology 241 172-182.

Sapienza C, Peterson AC, Rossant J \& Balling R 1987 Degree of methylation of transgenes is dependent on gamete of origin. Nature 328 251-254.

Shi W \& Haaf T 2002 Aberrant methylation patterns at the two-cell stage as an indicator of early developmental failure. Molecular Reproduction and Development 63 329-334.

Shi W, Dirim F, Wolf E, Zakhartchenko V \& Haaf T 2004 Methylation reprogramming and chromosomal aneuploidy in in vivo fertilized and cloned rabbit preimplantation embryos. Biology of Reproduction 71 340-347.

Sun QY \& Nagai T 2003 Molecular mechanisms underlying pig oocyte maturation and fertilization. Journal of Reproduction and Development 49 347-359.

Sutovsky P \& Schatten G 1997 Depletion of glutathione during bovine oocyte maturation reversibly blocks the decondensation of the male pronucleus and pronuclear apposition during fertilization. Biology of Reproduction 56 1503-1512.

Tattini A \& Mattioli M 1988 Induzione di estri fertili mediante somministrazione di PMSG e hCG a scrofette e a scrofe in anestro. Selezione Veterinaria 29 351-353.

Ward WS \& Coffey DS 1991 DNA packaging and organization in mammalian spermatozoa: comparison with somatic cells. Biology of Reproduction 44 569-574.

Ward WS \& Zalensky AO 1996 The unique, complex organization of the transcriptionally silent sperm chromatin. Critical Reviews in Eukaryotic Gene Expression 6 139-147.

Wolffe AP \& Matzke MA 1999 Epigenetics: regulation through repression. Science 286 481-486. 
Worrad DM, Turner BM \& Schultz RM 1995 Temporally restricted spatial localization of acetylated isoforms of histone $\mathrm{H} 4$ and RNA polymerase II in the 2-cell mouse embryo. Development $\mathbf{1 2 1}$ 2949-2959.

Wrenzycki C \& Niemann H 2003 Epigenetic reprogramming in early embryonic development: effects of in-vitro production and somatic nuclear transfer. Reproductive Biomedicine Online 7 649-656.

Wright SJ \& Longo FJ 1988 Sperm nuclear enlargement in fertilized hamster eggs is related to meiotic maturation of the maternal chromatin. Journal of Experimental Zoology 247 155-165.

Wu G, Bazer FW, Cudd TA, Meininger CJ \& Spencer TE 2004 Maternal nutrition and fetal development. Journal of Nutrition 134 $2169-2172$

Young LE \& Beaujean N 2004 DNA methylation in the preimplantation embryo: the differing stories of the mouse and sheep. Animal Reproduction Science 82-83 61-78.
Young LE, Fernandes $\mathrm{K}$ McEvoy TG Butterwidth SC, Gutierrez CG, Carolan C, Broadbent PJ, Robinson JJ, Wilmut I \& Sinclair KD 2001 Epigenetic change in IGF2R is associated with foetal overgrowth after sheep embryo culture. Nature Genetics 27 $153-154$.

Zuelke KA, Jeffay SC, Zucker RM \& Perreault SD 2003 Glutathione $(\mathrm{GSH})$ concentrations vary with the cell in maturing hamster oocytes, zygotes, and pre-implantation stage embryo. Molecular Reproduction and Development 64 106-112.

Received 22 March 2005

Accepted 29 March 2005 